\title{
METHODS FOR DETERMINATION OF THE PARAMETERS OF A MACHINE GUN SUSPENSION MOUNTED ON AN ARMOURED VEHICLE
}

\author{
Svilen SPIRDONOV, Svilen STEFANOV \\ "Vasil Levski" National Military University, Veliko Tarnovo, Bulgaria \\ saspirdonov@nvu.bg
}

\begin{abstract}
The following report shows methods for determination of the coefficients of stiffness and damping, for softening the vibrations, which ensue in an armoured vehicle's suspension from the shooting of a mounted machine-gun. The methods are based on a model of the movement smoothness, in which is additionally included the signal of the machine gun's recoil.
\end{abstract}

Keywords: shooting, machine gun suspension, stiffness, damping

\section{Introduction}

The process of shooting from armoured vehicles has a frequency character and under certain conditions, it may cause resonance in the vehicle's suspension. For analysis of these processes in [1] is developed a dynamical model of the machine with seven degrees of freedom (DOF) - figure 1 .

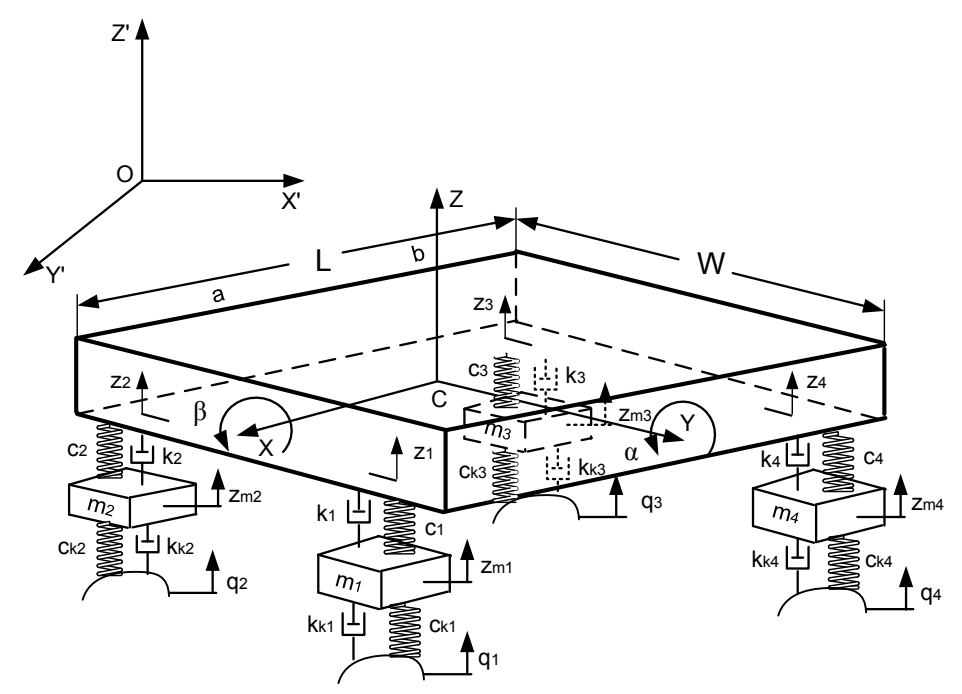

Figure 1: Dynamical model of the machine with seven DOF

For the basis of the model is used Mercedes G270 CDI, which is equipped with 7,62 mm Kalashnikov's machine gun and 12,7 mm NSVT machine gun. The model [2] allows a research on vibrations, which ensue in the vehicle's suspension from the shooting of different types of mounted machine-guns by introducing energy of recoil. Based on experiments made in [2] and [3], it is understood that when the shooting is at place the maximum mean square angular displacement of the barrel is 
32,4722 thousandths, and when the shooting is in movement on macadam 44,4433 thousandths.

We know that one-thousandths mean square angular deviation of the barrel on thousand meters gives deviation of one meter in vertical. Therefore the vertical deviation of shooting is forty-four meter.

If we want to reduce the angular displacement, we have to design a damper in the gun-carriage.

\section{Introducing energy of recoil}

Classical damper in passive type [4] has two components. First - which collects energy, and second - which absorbs energy of recoil. Figure 2 shows fundamental schema of that mechanism with spring and damper.

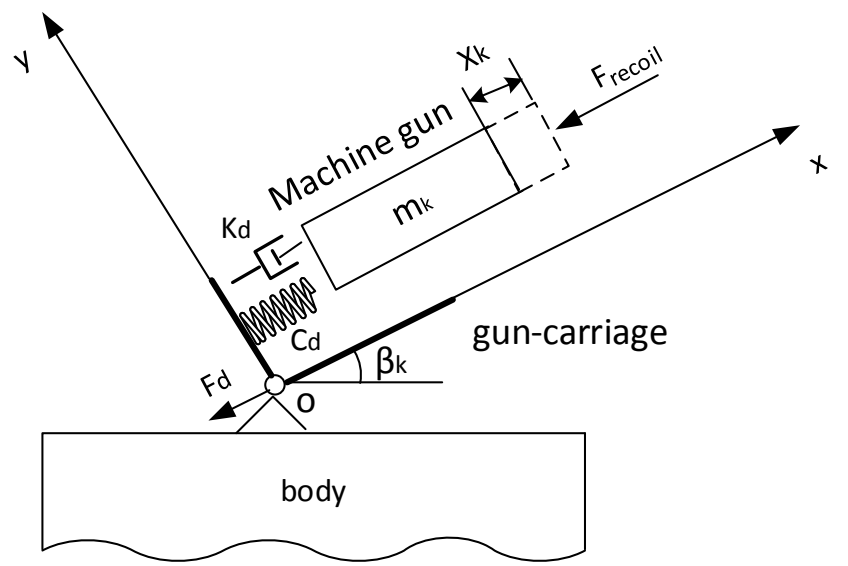

Figure 2: Fundamental schema of an elastic suspension

In that case, the machine gun and the elastic suspension have one degree of freedom movement on axis $X$. On that base is derived a differential equation of the machine gun's motion, which is:

$$
m_{k} . \ddot{x}_{k}+k_{d} \cdot \dot{x}_{k}+c_{d} \cdot x_{k}=F_{\text {oтк }}
$$

where:

- $m_{k}$ - machine gun's mass, $k g$;

- $\mathrm{k}_{\mathrm{d}}$ - coefficient of damping, N.s/m;

$-\mathrm{c}_{\mathrm{d}}$ - coefficient of stiffness, $\mathrm{N} / \mathrm{m}$;

- $\mathrm{F}_{\text {rcl. }}$ - force of recoil, $N$;

- $\mathrm{x}_{\mathrm{k}}$ - movement on axis $X$.

From the differential equations is derived the transmission function of the motion.

$$
W_{k}=\frac{1}{m_{k} \cdot p^{2}+k_{d} \cdot p+c_{d}}
$$

It is known from the mechanics, that in such case the force transmits trough the spring. Then value of the force $F_{d}$ in the point of attaching is:

$F_{d}=c_{d} \cdot \Delta x_{k}$
$F_{d}$ - value of the force in the point of attaching.

If we accept, that $x_{k}=0$ when the machine gun is in front position without shooting, then $\Delta x_{k}=x_{k}$. In that case the transmission function between the recoil's force and the force in the point of attaching is:

$W_{d}=\frac{F_{d}}{F_{o m \kappa}}=\frac{c_{d}}{m_{k} \cdot p^{2}+k_{d} \cdot p+c_{d}}$

The spectral density in the force of the point of attaching is:

$$
S_{F_{d}}=S_{F_{\text {отк. }}} \cdot W_{k}(j \omega) \cdot W_{k}(-j \omega)
$$

The decomposition of that force on the axes of the coordinate system, connected with the vehicle's body, may be also considered as a transmission function. In that case:

$$
\begin{aligned}
& S_{F_{z}}=S_{F_{d}} \cdot W_{z}(j \omega) \cdot W_{z}(-j \omega) ; \\
& S_{M_{x}}=S_{F_{d}} \cdot W_{x}(j \omega) \cdot W_{x}(-j \omega) ; \\
& S_{M_{y}}=S_{F_{d}} \cdot W_{y}(j \omega) \cdot W_{y}(-j \omega),
\end{aligned}
$$


where:

- $W_{z}=\sin \beta_{k}$;

- $W_{x}=\left(\cos \beta_{k} \cdot \sin \alpha_{k}\right) \cdot z_{t}-\left(\sin \beta_{k}\right) \cdot y_{t}$;

- $W_{y}=-\left(\cos \beta_{k} \cdot \cos \alpha_{k}\right) \cdot z_{t}+\left(\sin \beta_{k}\right) \cdot x_{t}$

The spectral densities from the example (6) are used as inputs in the matrix of the spectral densities, which are described in [1].

\section{Determination of the coefficients of the elastic suspension}

A key step in the synthesis of the elastic suspension is the determination of the stiffness coefficient $C_{d}, N / m$ and the damping coefficient $K_{d}, N . s / \mathrm{m}$. Figure 3 shows mean square angular deviations of the bore line of the machine gun's barrel, in different values of these parameters. The data is for shooting at place, with a position of the machine gun in horizontal plane at $90^{\circ}$ angle and $0^{\circ}$ in vertical plane.

Figure 3 shows, that the function does not have an extremum, which means that there is no optimal solution. Therefore, for the project of the elastic suspension we need to choose a value of one of the parameters $C_{d}$ or $K_{d}$ and the permissible deviation and to determinate the value of the other parameter from the scheme.

If we accept that the permissible mistake is 2 thousandths, the stiffness coefficient $C_{d}$ is $8 \mathrm{~N} / \mathrm{m}$, then the value of the damping coefficient turns out $300 \mathrm{~N} . \mathrm{s} / \mathrm{m}$.

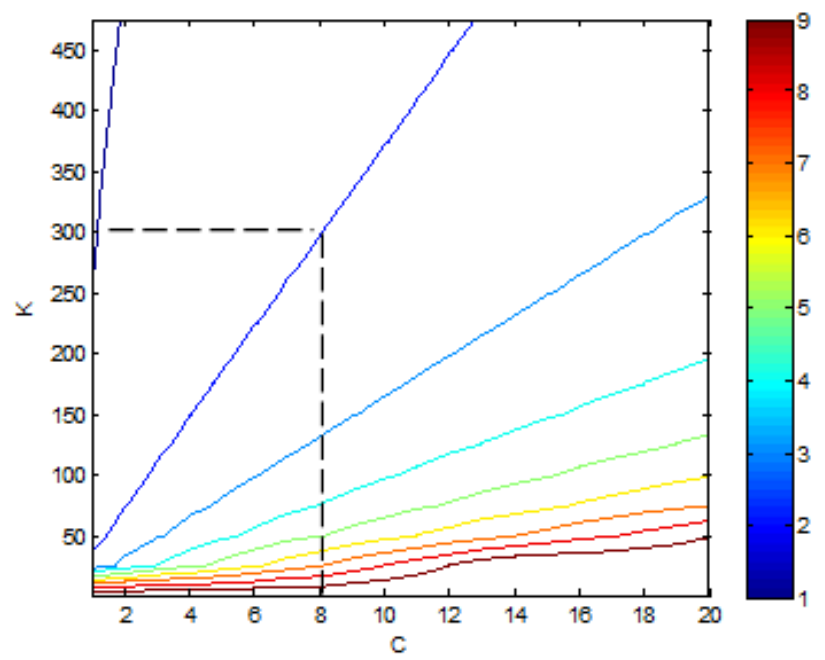

Figure 3: Mean square angular deviations of the bore line of 12,7 mm NSVT machine gun's barrel in different values of the coefficients $C d$ and $K d$ of the elastic suspension in thousands

The great value of the damping coefficient $K_{d}$ and the little value of the stiffness coefficient $C_{d}$ show, that the suspension has to be a recoil system, not a classical elastic suspension.

4. Research on the deviations in the machine gun's bore line in shooting at place with an elastic suspension

There were held a numerical experiments for determination of the mean square angular deviations of the amplitude's oscillations rising in the body and the suspension of the vehicle, in shooting at place with $12,7 \mathrm{~mm}$ NSVT machine gun with an elastic suspension. Comparing the results with these at [2], shows that in the worst position of shooting - horizontal angel $90^{\circ}$, vertical angel $0^{\circ}$ - the roll decreases 16 times. In the most favorable position of shooting - $0^{\circ}$ horizontal angel and $0^{\circ}$ vertical angel - all deviations, decrease 14 times. If we use an elastic suspension with this value of the damping 
and stiffness coefficients, the mean square angular deviations in the vehicle's suspension decrease from $26 \mathrm{~mm}$ to 1,6 $\mathrm{mm}$.

In these results, we may draw a conclusion, that the elastic suspension will raise the efficiency of shooting 10 times. In addition, the chance of occurrence of damage in the vehicle's body and suspension is brought to zero.

5. Research on the deviations in the machine gun's bore line in shooting in movement with an elastic suspension

Series of numerical experiments were held for the determination of the elastic suspension's influence for the deviation of the bore line of the machine gun's barrel. The experiments were carried out in different types of roads and different positions of the machine gun.

Input data:

- type of the road - asphalt (1), pavement (2), macadam (3);

- horizontal angel of the machine gun - $0^{\circ}$ and $90^{\circ}$;

- vertical angel of the machine gun - $0^{\circ}$;

- speed $0-90 \mathrm{~km} / \mathrm{h}$.

Figure 4, 5 and 6 show the mean square angular deviations of the bore line of the machine gun's barrel with and without damper.

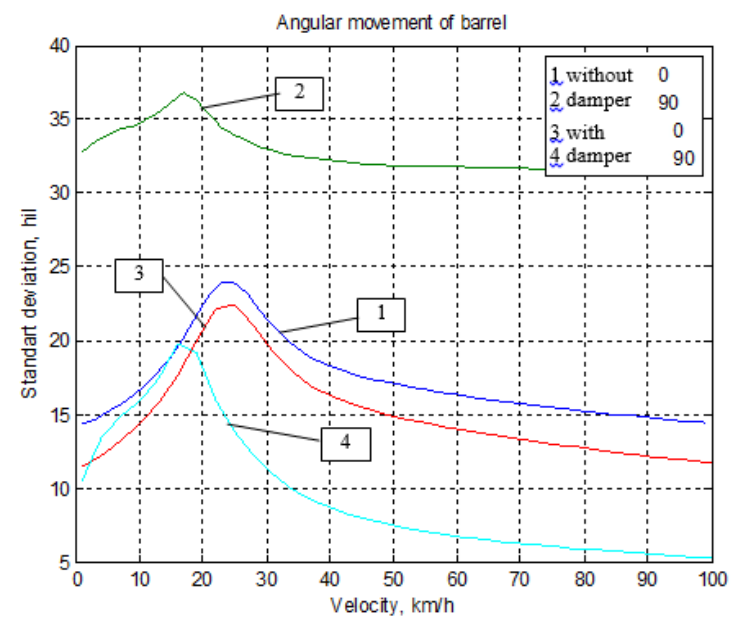

Figure 4: Mean square angular deviations of the bore line of the machine gun's barrel in shooting in movement on asphalt

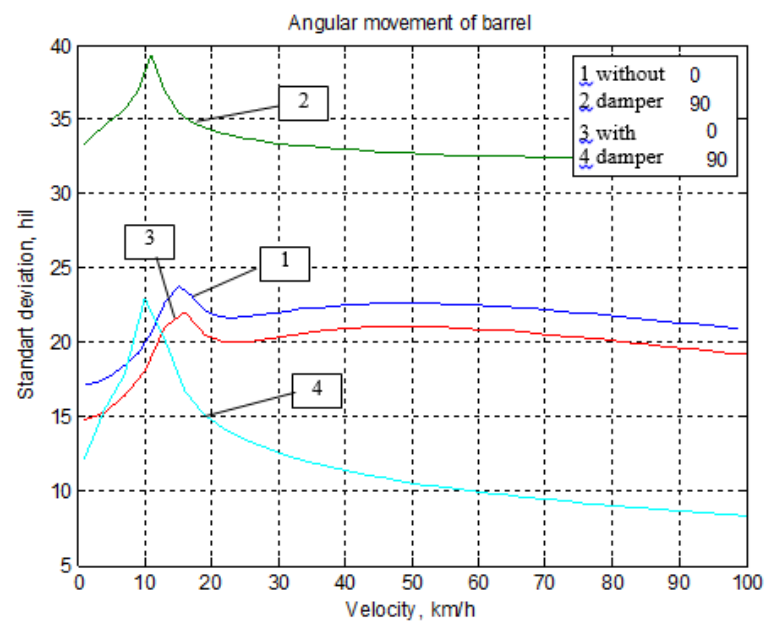

Figure 5: Mean square angular deviations of the bore line of the machine gun's barrel in shooting in movement on pavement 


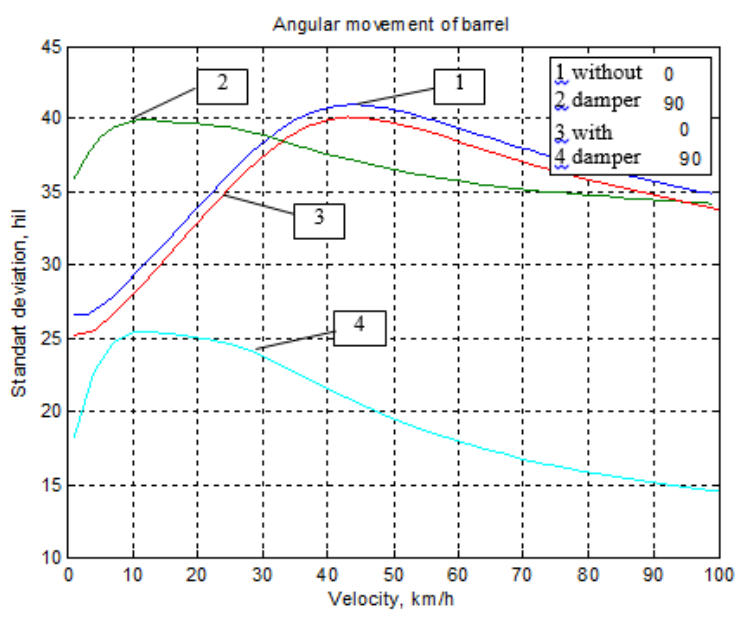

Figure 6: Mean square angular deviations of the bore line of the machine gun's barrel in shooting in movement on macadam

This figure shows that the elastic suspension influences a lot in $90^{\circ}$ horizontal position and less in $0^{\circ}$ horizontal position. This elastic suspension excludes influence of horizontal position of the machine gun like essential factor of distraction of shooting at motion. Basic interference is road roughness.

In this elastic suspension, we cannot decrease the influence of the road, but we can reduce the dissipation of the shooting and the influence on the vehicle's suspension.

\section{Conclusions}

1. The spectral densities received on the exit of the elastic suspension are entrance for the vehicle's body end suspension. The decomposition of that force of recoil is a system of transfer functions and the model is simplified.
2. The deviations of the barrel in function of damping and stiffness coefficient do not have an extremum. Therefore, for the project of the elastic suspension we need to choose a value of one of the parameters $C_{d}$ or $K_{d}$ and the permissible deviation and to determinate the value of the other parameter from the figure 3 . The little value of the stiffness coefficient $C_{d}$ shows, that the suspension has to be a recoil system.

3. In shooting at place with an elastic suspension in the worst position the roll decreases 16 times. This increases the efficiency of shooting and reduces the dissipation.

4. An elastic suspension in passive type cannot decrease the influence of the road, but it can reduce the dissipation of the shooting and the influence on the vehicle's suspension.

\section{References}

[1] Spirdonov S., Method of approach for using the basic equation of statistical dynamics for analyzing the frequency response of the body of an armoured vehicle, Proceedings of 2nd International Scientific Conference TECHNICS. TECHNOLOGIES. EDUCATION. SAFETY, pp. 1310-3946, Veliko Tarnovo, Bulgaria, May, 2014.

[2] Spirdonov S., Stefanov S., Yotkov T., Research on the vibro-dynamical processes, which ensue in an armoured vehicle suspension from the shooting of mounted machine-guns at place, Proceedings of Annual University Science Conference of National Military University "Vasil Levski”, pp. 1314-1937, Veliko Tarnovo, Bulgaria, July, 2014. 
[3] Spirdonov S., Lilov I., Georgiev I., Research on the diffusion in vertical direction during shooting with a weapon mounted on an armoured vehicle under different movement regimen, Proceedings of Annual University Science Conference of National Military University "Vasil Levski", pp. 1314-1937, Veliko Tarnovo, Bulgaria, July, 2014.

[4] Spirdonov S., Research on the efficiency of the armoured vehicles during peacekeeping operations, Dissertation, Veliko Tarnovo, National Military University "Vasil Levski", 2014, 234 p. 